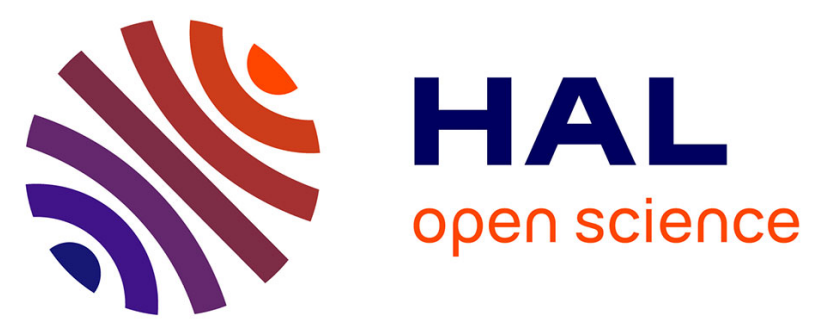

\title{
Introduction of a NIa proteinase cleavage site between the reporter gene and HC-Pro only partially restores the biological properties of GUS- or GFP-tagged LMV \\ Sylvie German Retana, E. Redondo, G. Tavert-Roudet, Olivier O. Le Gall, Thierry T. Candresse
}

\section{To cite this version:}

Sylvie German Retana, E. Redondo, G. Tavert-Roudet, Olivier O. Le Gall, Thierry T. Candresse. Introduction of a NIa proteinase cleavage site between the reporter gene and HC-Pro only partially restores the biological properties of GUS- or GFP-tagged LMV. Virus Research, 2003, 98 (2), pp.151162. hal-02676308

\author{
HAL Id: hal-02676308 \\ https://hal.inrae.fr/hal-02676308
}

Submitted on 31 May 2020

HAL is a multi-disciplinary open access archive for the deposit and dissemination of scientific research documents, whether they are published or not. The documents may come from teaching and research institutions in France or abroad, or from public or private research centers.
L'archive ouverte pluridisciplinaire HAL, est destinée au dépôt et à la diffusion de documents scientifiques de niveau recherche, publiés ou non, émanant des établissements d'enseignement et de recherche français ou étrangers, des laboratoires publics ou privés. 


\title{
Introduction of a NIa proteinase cleavage site between the reporter gene and HC-Pro only partially restores the biological properties of GUS- or GFP-tagged LMV
}

\author{
Sylvie German-Retana*, Elise Redondo ${ }^{1}$, Geneviève Tavert-Roudet, \\ Olivier Le Gall, Thierry Candresse
}

Plant-Virus Interactions, IBVM, INRA, BP 81, 33883 Villenave d'Ornon Cedex, France

Received 18 June 2003; received in revised form 4 September 2003; accepted 10 September 2003

\begin{abstract}
Lettuce mosaic virus (LMV) isolates LMV-E and LMV-0 differ in their virulence on lettuce varieties carrying the $\mathrm{mol}^{2}$ resistance gene, which reduces viral accumulation and blocks the expression of symptoms after infection with avirulent isolates such as LMV-0. Previous work had indicated that reporter genes such as GUS or GFP affect the biological properties of recombinant LMV isolates in both susceptible and resistant lettuce varieties when fused to the N-terminus of the viral protein HC-Pro. The impact of the addition of a cleavage site for the NIa proteinase between the reporter gene and HC-Pro was evaluated, in an effort to recover the full spectrum of the biological properties of parental isolates. Symptoms, accumulation, cell-to-cell and long distance movement of the recombinant viruses containing the NIa cleavage site were studied in susceptible and $m o l^{2}$ lettuce varieties. Both LMV-0 and LMV-E recombinant viruses recovered the behaviour of their wild-type parent in susceptible plants upon addition of the NIa cleavage site. While the recombinant LMV-E modified in this way recovered the breaking properties of its wild-type counterpart in $m o l^{2}$ plants, similar modification of the LMV-0 derived recombinants failed to rescue a severe inhibition in systemic accumulation in $\mathrm{mol}^{2}$ plants, despite the fact that neither cell-to-cell movement nor phloem loading or unloading seemed to be severely affected.
\end{abstract}

(C) 2003 Elsevier B.V. All rights reserved.

Keywords: Potyvirus; LMV; GFP; GUS; Resistance gene; Lettuce

\section{Introduction}

Lettuce mosaic virus (LMV, genus Potyvirus) is one of the most destructive viruses in lettuce (Lactuca sativa) crops all over the world (Dinant and Lot, 1992). The LMV genome consists of a positive-strand RNA of 10,080 nucleotides (Revers et al., 1997a). The RNA is polyadenylated at its $3^{\prime}$ end, linked to a viral protein (VPg) at its $5^{\prime}$ end, and encodes a single polyprotein that is processed by three virus-encoded proteinases (Dougherty et al., 1990; Reichman et al., 1992). Two alleles of a gene named $\mathrm{mol}$ in lettuce are associated with resistance to LMV in a recessive manner (Bannerot et al., 1969; Ryder, 1970). We have recently discovered that mol encodes the translation initiation factor eIF4E

\footnotetext{
* Corresponding author. Fax: +33-5-57122384.

E-mail address: german@bordeaux.inra.fr (S. German-Retana).

1 Present address: Biogemma, 24 avenue des Landais, 63170 Aubière, France.
}

(Nicaise et al., 2003). LMV isolates differ in their ability to infect and produce symptoms in lettuce genotypes carrying $\mathrm{mol}^{1}$ or $\mathrm{mol}^{2}$ (Pink et al., 1992a; Bos et al., 1994; Revers et al., 1997b). Depending on the virus isolate/host cultivar combination, mol conveys either full resistance (absence of detectable virus accumulation) or tolerance (systemic virus accumulation but failure to induce symptoms). The two LMV isolates used in this study differ in their pathogenicity, resistance-breaking and seed transmission properties. LMV-E is a resistance-breaking isolate that induces severe symptoms on susceptible and resistant cultivars, and is not seed-borne (Pink et al., 1992b). LMV-0 is a seed-borne isolate that induces relatively milder symptoms on susceptible cultivars. In plants carrying $m o l^{2}$, LMV-0 is generally able to mount a systemic invasion with much reduced accumulation and symptoms failing to develop. In susceptible plants, LMV-0 and LMV-E induce different types of symptoms but accumulate to similar levels (Redondo et al., 2001). 
GFP and GUS markers have been largely used to elucidate the role of virus-encoded genes and to follow viral invasion of host and non-host plants (Dolja et al., 1992; Baulcombe et al., 1995; Oparka et al., 1997; Roberts et al., 1997; Sudarshana et al., 1998; Wang et al., 1999; Cheng et al., 2000; Cohen et al., 2000; MacFarlane and Popovich, 2000; Arazi et al., 2001). Previous work with LMV has indicated that viable and stable GUS-or GFP-tagged recombinant isolates can be obtained by inserting the reporter genes in frame between the P1 and HC-Pro coding regions so that the reporter protein is expressed as an N-terminal fusion to HC-Pro (German-Retana et al., 2000). However, the biological properties of such recombinant viruses (named LMV-GUSHC or LMV-GFPHC) were significantly altered as compared to those of the wild-type parents from which they were derived (German-Retana et al., 2000; Candresse et al., 2002). Such modifications included attenuation of symptom severity for both LMV-0 and LMV-E, reduction of accumulation of LMV-E in susceptible hosts, and loss of aphid transmissibility (German-Retana et al., 2000). In addition, the systemic movement of the GUS-or GFP-tagged isolates was differentially affected in $\mathrm{mol}^{1}$ or $\mathrm{mol}^{2}$-carrying lettuce varieties. The LMV-0 recombinants were unable to systemically invade mol plants while the LMV-E derived recombinant maintained the ability to overcome $\mathrm{mol}^{1}$. However, LMV-E-GFPHC lost the ability to overcome $\mathrm{mol}^{2}$ and did not move systemically in plants carrying this gene (German-Retana et al., 2000; Candresse et al., 2002).

In an effort to recover the full spectrum of biological properties of the parental isolates, an artificial cleavage site for the NIa viral proteinase was engineered between the reporter gene and HC-Pro to allow recovery of an unfused HC-Pro following maturation of the reporter-HC-Pro precursor. The symptoms, accumulation, and cell-to-cell and long distance movement of these recombinant viruses, named LMV-GUSclvHC or LMV-GFPclvHC, were studied in susceptible and mol lettuce varieties.

\section{Material and methods}

\subsection{Viral cDNAs}

The construction and characterisation of pLMV-EGFPHC and pLMV-E-GUSHC has been described previously (German-Retana et al., 2000). Similar constructs were prepared from an infectious cDNA of LMV-0 (Redondo et al., 2001). The plasmids pLMVclvHC, pLMV-GFPclvHC, and pLMV-GUSclvHC were obtained by inserting a doublestranded oligonucleotide encoding a consensus cleavage site recognised by the NIa viral proteinase (GDEVYHQ/ SG) in the SmaI site of the relevant pLMV-GUSHC or pLMV-GFPHC construct (Fig. 1). The sequences of the complementary oligonucleotides used were (sense: $5^{\prime}$ GGGGACGAAGTATACCACCAGTCCGGA-3') and (antisense: 5'-TCCGGACTGGTGGTATACTTCGTCCCC-3').
Annealing of these oligonucleotides was achieved by boiling $1 \mathrm{nmol}$ of each oligonucleotide for $5 \mathrm{~min}$ in $20 \mathrm{mM}$ Tris- $\mathrm{HCl} \mathrm{pH} 7.4,2 \mathrm{mM} \mathrm{MgCl} 2,5 \mathrm{mM} \mathrm{NaCl}$ and allowing the reaction to cool down slowly to $50^{\circ} \mathrm{C}$. Ten picomoles of annealed oligonucleotides were then ligated into the SmaI site of each of the pLMV-GFPHC or pLMV-GUSHC constructs.

\subsection{Plant material and inoculation}

The susceptible lettuce cultivar "Trocadéro" was routinely used for virus propagation. The cDNAs of all recombinant viruses were initially inoculated into Trocadéro plants as previously described (German-Retana et al., 2000). They were than back-inoculated mechanically into plants of the susceptible varieties Trocadéro, Salinas, or the early flowering line 8720 M (Ryder, 1996), kindly provided by Dr E. Ryder (USDA Salinas), or into the $m o l^{2}$-containing variety Salinas 88. Salinas and Salinas 88 are near isogenic lines differing mainly in the $\mathrm{mol}^{2}$ gene (Ryder, 1991; Nicaise et al., 2003).

\subsection{Grafting of lettuce plants}

Salinas or Salinas 88 rootstocks were inoculated with the relevant recombinant virus 2 weeks prior to the grafting. Healthy etiolated stems of Salinas or of Salinas 88 were then grafted onto the rootstocks using inverted saddle grafts (Kains and McQuesten, 1960). Briefly, a V-shaped notch was made in the stem of the rootstock and a corresponding V-shaped wedge was cut in the stem of the scion to be grafted. Both fresh cuts were placed together and wrapped tightly. Grafted plants were kept in "mini green-houses" to prevent dehydration of the scion during recovery from grafting. After usually 9 days, the recovered plants, as shown by the survival of the scion, were then transferred to an insect-proof green-house with standard conditions ( $16 \mathrm{~h}$ daylight, $20-30^{\circ} \mathrm{C}$ ).

\subsection{Detection of GUS and GFP expression}

Histochemical GUS staining was performed following a protocol slightly modified from that of Jefferson (1987). Vacuum was used to infiltrate the GUS staining solution supplemented with $0.2 \%(\mathrm{v} / \mathrm{v})$ Triton X-100 into leaf fragment or roots. $\mathrm{K}_{4}\left[\mathrm{Fe}(\mathrm{CN})_{6}\right]$ and $\mathrm{K}_{3}\left[\mathrm{Fe}(\mathrm{CN})_{6}\right]$ at $500 \mathrm{mM}$ concentrations were added to the GUS buffer in order to avoid artefacts and to localise the blue precipitate only in the cytoplasm of the cells where the GUS activity is expressed (De Block and Debrouwer, 1992). The reaction was usually performed overnight at $37^{\circ} \mathrm{C}$. The on-line software image analysis "Image Tool for Windows" (University of Texas Health Science Center San Antonio) was used to measure and compare the area of the infection foci on inoculated leaves.

Expression of GFP at the whole plant level was visualised using a $100 \mathrm{~W}$, hand-held, long-wave UV spot-light lamp (Model B-100; UV Products, Upland, CA). At the 
LMV-0

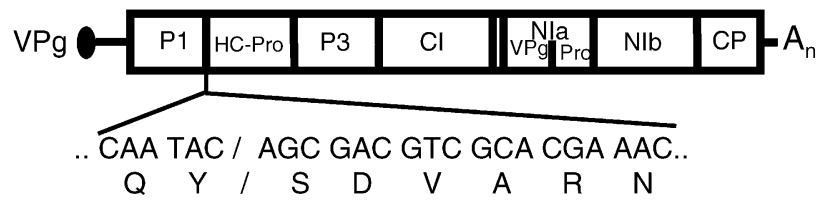

LMV-0-GFPHC

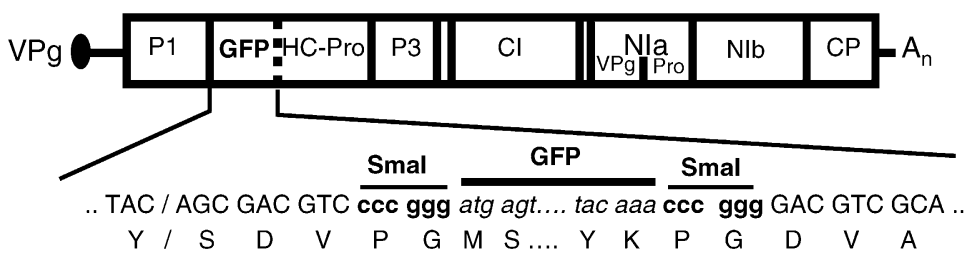

LMV-0clvHC

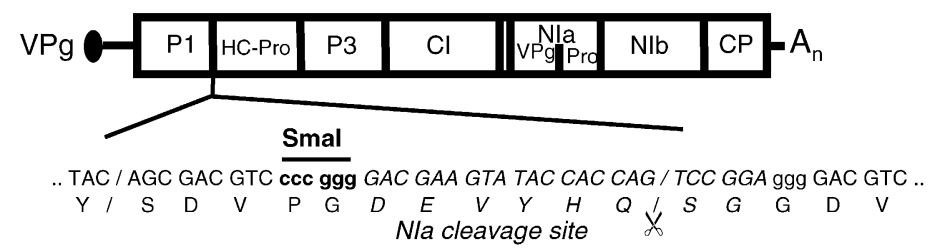

LMV-0-GFPclvHC

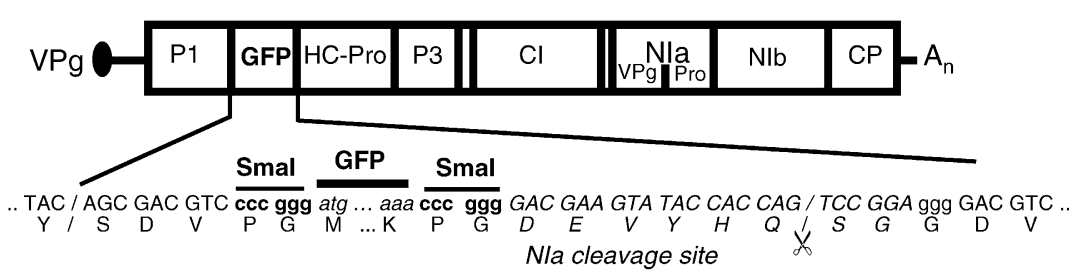

LMV-0-GUScIvHC

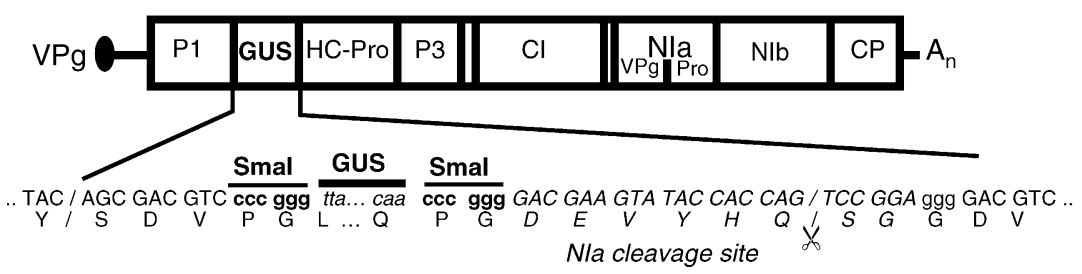

Fig. 1. Detail of the modified sequences in recombinant LMV. Schematic illustration of Lettuce mosaic virus common isolate (LMV-0) genome and tagged recombinants (green fluorescent protein: GFP, $\beta$-glucuronidase: GUS). The details of the junction between P1 and HC-Pro sequence in each of the recombinant viruses are shown. Nucleotide and amino acid sequences modified in LMV-0clvHC, LMV-0-GFPHC, LMV-0-GFPclvHC and LMV-0-GUSclvHC with respect to wild-type LMV-0, are indicated below each diagram. The octapeptide recognised by the NIa protease is in italics and the cleavable scissile bond artificially introduced is schematised by scissors.

tissue level, GFP expression was examined by fluorescence microscopy using an instrument equipped with GFP(R)LP,HQ-FITC-LP Filters (Eclipse 800, Nikon, Tokyo, Japan) and a fluorescence stereomicroscope (MZ FLIII, Leica Microsystems, Heerburg, Switzerland) equipped with a filter with an excitation window at $470 \pm 20 \mathrm{~nm}$ and an arrest window at $525 \pm 25 \mathrm{~nm}$.

\subsection{Protein analysis and Western blotting}

Leaf tissue was ground in electrophoresis loading buffer $[125 \mathrm{mM}$ Tris-HCl pH 6.8, $10 \%$ SDS, 25\% $\beta$-mercaptoethanol] using a $1 / 5(\mathrm{w} / \mathrm{v})$ grinding ratio. Following boiling for $3 \mathrm{~min}$, the homogenate was centrifuged at $20,000 \times g$ for $10 \mathrm{~min}$. Proteins were separated on $10 \%$ 
polyacrylamide-SDS gels and blotted onto nitrocellulose membranes. The membranes were probed with either polyclonal antibodies raised against GFP (Invitrogen, Carlsbad, CA) or with a monoclonal antibody raised against LMV HC-Pro protein (Roudet-Tavert et al., 2002), and anti-rabbit or anti-mouse IgGs coupled with alkaline phosphatase were used as secondary antibodies. Detection was finally achieved using an NBT-BCIP colorimetric reaction.

\subsection{Quantification of viral accumulation}

Viral concentrations were estimated by ELISA as described by Clark and Adams (1977), and the viral RNA was detected by dot-blot hybridisation with a dig-labeled in vitro transcribed cRNA probe as described by Brault et al. (1993).

\section{Results}

\subsection{A NIa cleavage site introduced between the reporter gene and HC-Pro is efficiently utilised}

A LMV consensus cleavage site (GDEVYHQ/SG, where the slash indicates the bond cleaved by the proteinase) was determined by alignment of the cleavage sites recognised by the NIa proteinase in the LMV sequence. A synthetic DNA fragment encoding this octapeptide was introduced between the GUS or GFP reporter gene and the HC-Pro of recombinants pLMV-GUSHC and pLMV-GFPHC derived from either LMV-0 or LMV-E. The four new constructs were named pLMV-x-GUSclvHC and pLMV-x-GFPclvHC, respectively, where $\mathrm{x}$ indicates the parental virus (Fig. 1). In these viruses, two glycine residues absent from the non-recombinant virus are predicted near the $\mathrm{N}$-terminus of HC-Pro after NIa cleavage. As a control, a recombinant in which the NIa site was added, without any reporter gene was also constructed and named LMV-0-clvHC (Fig. 1). All recombinant viruses were infectious as shown by the development of disease after inoculation by particle bombardment of the susceptible lettuce variety "Trocadéro". Western blots of proteins extracted from Trocadéro leaves 15 days post-inoculation (dpi) demonstrated that the majority of the GFP-HC-Pro fusion protein was processed, as expected (Fig. 2A). While only the $80 \mathrm{kDa}$ GFP-HC-Pro fusion protein was detected in the plants infected with LMV-0-GFPHC (lane 2), in extracts of plants infected with LMV-0-GFPclvHC (lane 1), HC-Pro was mostly present in a processed form which co-migrated with the HC-Pro detected in wild-type LMV-0 infected plants (lane 3). A low amount of GFP-HC-Pro fusion protein (estimated at less than $10 \%$ of the amount of free HC-Pro) was still detectable (lane 1). These results were confirmed by probing a similar blot with a GFP-specific antiserum (Fig. 2B). Similar results were obtained at 3,4 and 7 weeks after inoculation, for both LMV-0 and LMV-E GFP derivatives, without any significant difference in the level of accumulation of free

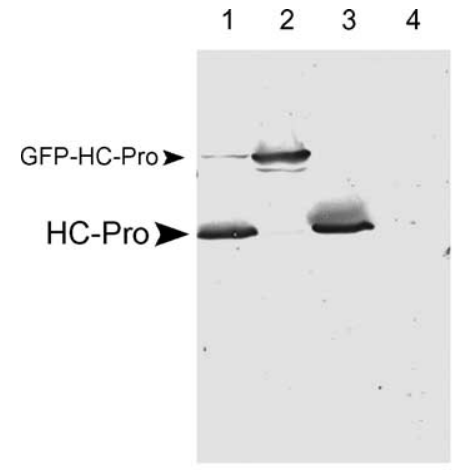

(A)

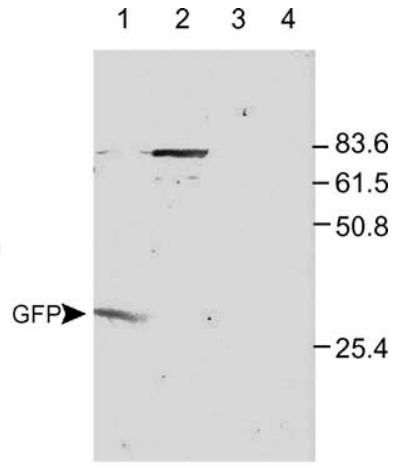

(B)
Fig. 2. Western blot analysis of the processing of HC-Pro in LMV recombinants. Western blot analysis of proteins accumulated in "Trocadéro" lettuce plants uninfected (lane 4) or infected with wild-type LMV-0 (lane 3), LMV-0-GFPclvHC (lane1), and LMV-0-GFPHC (lane 2) 15 dpi. Electrophoresis was in a $10 \%$ polyacrylamide gel. The protein blot was reacted with anti-HC-Pro monoclonal antibody (A) or anti-GFP polyclonal antibody (Invitrogen) (B). The positions of HC-Pro, GFP and the GFP-HC-Pro fusion are indicated by arrows on the left. The electrophoretic mobilities and $\mathrm{Mr}$ in $\mathrm{kDa}$ of prestained molecular weight markers ladders (Invitrogen) run in the same gels, are indicated on the right of panel (B).

HC-Pro (data not shown). These results showed that the introduced NIa cleavage site was efficiently utilised, allowing the processing of about $90 \%$ of the fusion protein to the expected GFP and HC-Pro cleavage products.

\subsection{The effect of the insertion of a NIa cleavage site on symptoms and viral accumulation depends on the viral isolate}

It has previously been shown that GFP or GUS fusion of the LMV-E HC-Pro has negative effects on symptom severity and accumulation of the virus in systemically infected leaves of a susceptible variety (German-Retana et al., 2000). Susceptible plants inoculated with a similar construct derived from LMV-0 (LMV-0-GFPHC) developed attenuated symptoms as compared to wild-type LMV-0 (Fig. 3C). Introduction of the artificial NIa cleavage site between the GFP and the HC-Pro sequences in these constructs restored symptom severity to that of the wild-type parents (Fig. 3A and $\mathrm{C}$ ). In particular, the stunting, leaf deformation and necrosis of young leaves, typical of LMV-E and abolished in LMV-E-GFPHC, were restored in LMV-E-GFPclvHC (Fig. 3B).

The accumulation of the GFP-tagged viruses in the susceptible lettuce variety salinas was estimated by enzyme-linked immunosorbent assay (ELISA), and compared with the accumulation of wild-type LMV at 15 dpi. As shown in Fig. 4A, no significant difference in accumulation was observed between LMV-0 and LMV-0-clvHC, LMV-0-GFPHC or LMV-0-GFPclvHC. In the plant variety Trocadéro, comparable results were obtained at 35 and 40 dpi by dot-blot hybridization experiments (data not shown). Thus, the GFP-tagging 


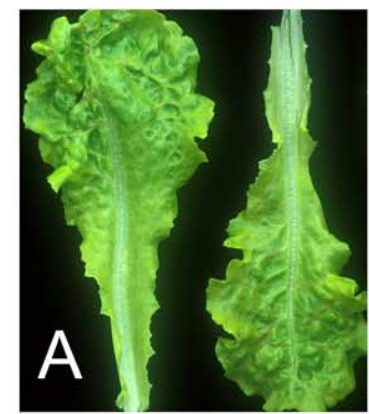

LMV-E-GFPclvHC LMV-E

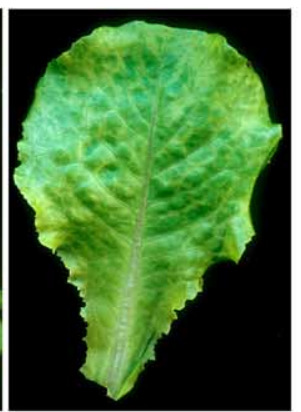

LMV-E-GFPHC

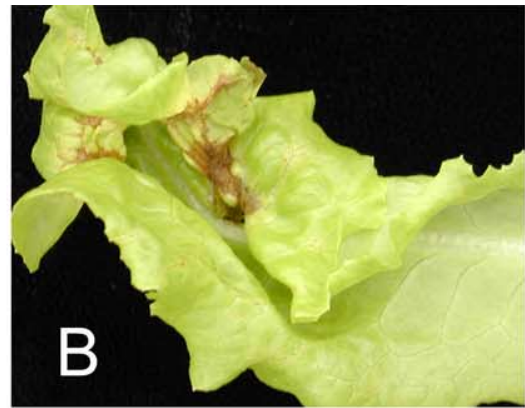

LMV-E-GFPclvHC
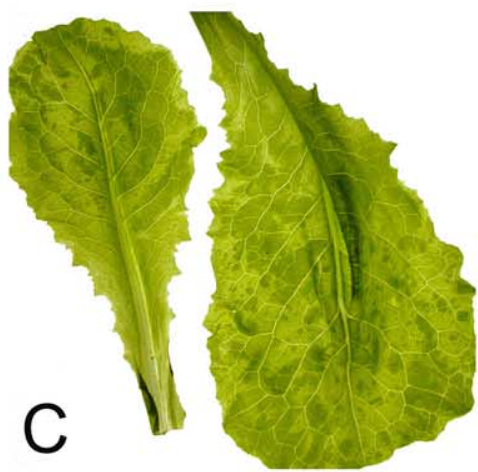

LMV-0

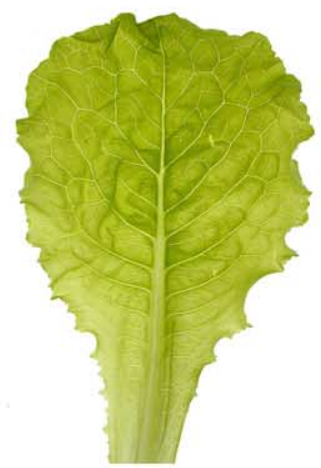

LMV-0-GFPHC

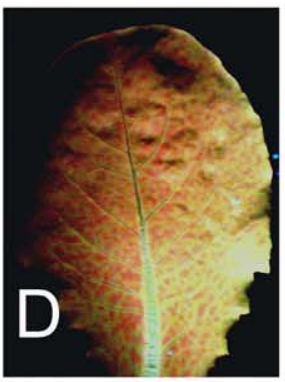

LMV-0-GFPclvHC

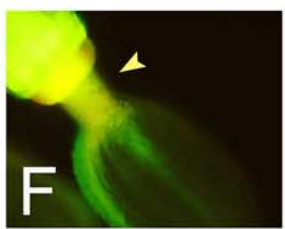

LMV-0-GFPclvHC

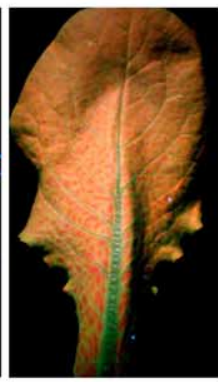

LMV-0-GFPHC

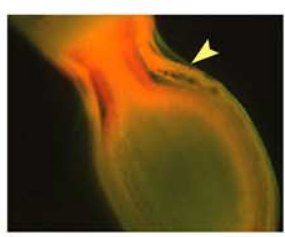

LMV-0

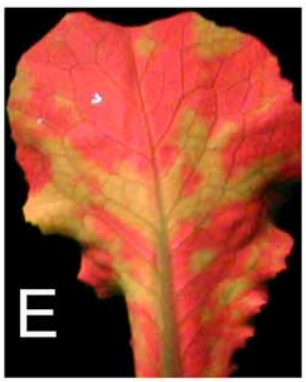

LMV-0-GFPclvHC

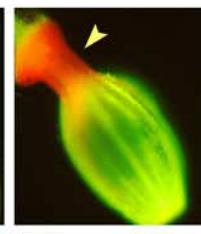

LMV-0-GFPHC

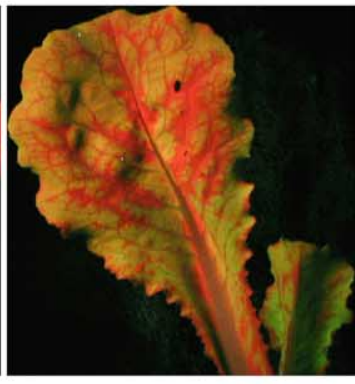

LMV-0-GFPHC

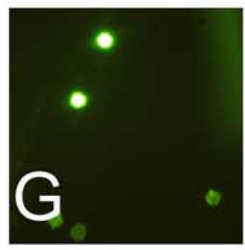

LMV-0-GFPclvHC

Fig. 3. Symptoms and distribution of tagged LMV in the susceptible lettuce "Trocadéro". (A): Symptoms induced by LMV-E, LMV-E-GFPHC and LMV-E-GFPclvHC 20 dpi. (B): Detail of the necrosis induced by LMV-E-GFPclvHC, characteristic of the wild-type LMV-E and absent from LMV-E-GFPHC infected plants. (C): Symptoms induced by LMV-0, LMV-0-GFPHC and LMV-0-GFPclvHC 20 dpi (these photographics were taken in trans-illumination, in order to improve the recognition of symptoms). (D) and (E): Visualisation under UV light of green fluorescent protein (GFP) fluorescence in LMV-0-GFPHC and LMV-0-GFPclvHC infected plants. (D): Fluorescence limited to vicinity of vein at 7 dpi. (E): Difference in the spatial distribution of fluorescence expanding to leaf blade at 20 dpi. (F): Detection of LMV-0-GFPclvHC and LMV-0-GFPHC in reproductive tissues of the lettuce accession 8720 M, 6 wpi. Representative example of detection of GFP in the lettuce ovary wall of LMV-0-GFPHC and LMV-0-GFPclvHC infected flowers, and in the neck between the style and ovary (yellow arrow). (G): Detection of GFP in pollen, only observed in the case of LMV-0-GFPclvHC.

of HC-Pro, with or without an added NIa cleavage site, had no effect on LMV-0 accumulation in susceptible lettuce hosts. In contrast, and as reported previously (German-Retana et al., 2000), the accumulation of LMV-E-GFPHC was significantly impaired at 15 dpi
(Fig. 4B), reaching only $28 \%$ of the accumulation level of LMV-E. Introduction of the NIa cleavage site restored accumulation of LMV-E-GFPclvHC to a level comparable to that of wild-type LMV-E in the susceptible variety (Fig. 4B). 
(A)

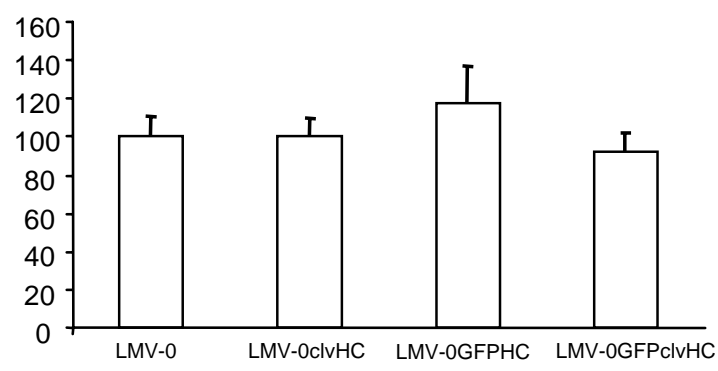

(B)

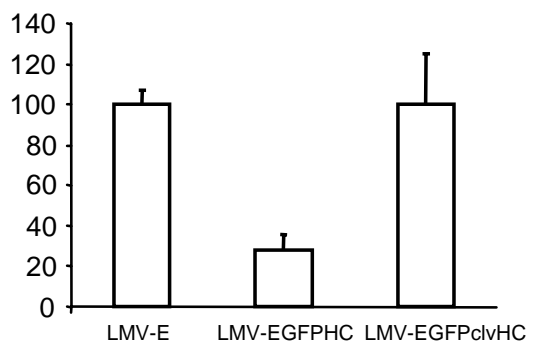

Fig. 4. Accumulation of GFP-tagged LMV-0 and LMV-E in susceptible lettuce "Salinas". The accumulation of GFP-tagged virus was determined by ELISA in three to four individual plants and normalised to the mean value $(=100 \%)$ measured similarly for the wild-type virus from which the recombinant viruses was derived. The samples were collected from developmentally equivalent non-inoculated symptomatic leaves (level 4 from the top of the plant) at $15 \mathrm{dpi}$. Experiments were repeated at least three times. The bars indicate standard deviations.

Taken together, these results indicated that the two isolates were differentially affected in their accumulation in host plants by the fusion tagging of their HC-Pro, which induced a severe reduction of the accumulation of LMV-E, but apparently no significant effect on LMV-0. They demonstrated further that introduction of the NIa cleavage site in the tagged recombinants allowed the recovery of symptom severity and accumulation levels typical of wild-type isolates.

\subsection{Introduction of an NIa cleavage site modifies the in planta distribution of tagged LMV-O in susceptible lettuce varieties}

GFP expression from LMV-E-GFPHC was still observed after prolonged propagation of the virus in the same host for many months (German-Retana et al., 2000). This was also the case for GFP-tagged viruses derived from LMV-0 (data not shown). We therefore tried to compare the accumulation of the LMV-0-derived recombinants in all organs and throughout the entire plant life cycle, including flowers and roots, using macroscopic and microscopic observation.

When the GFP-tagged LMV-0 derivatives were inoculated onto source leaves of the susceptible lettuce variety Trocadéro, circular fluorescent foci were apparent on the lamina within $4 \mathrm{dpi}$ (data not shown). At $7 \mathrm{dpi}$, the infection foci on the inoculated leaves had slightly increased in size, and symptoms developed on systemically infected leaves. At this stage, the GFP fluorescence pattern was fully super-imposable onto the developing vein-clearing symptoms, the fluorescence being limited to the vicinity of veins (Fig. 3D). No differences could be observed up to this stage between LMV-0-GFPHC and LMV-0-GFPclvHC (Fig. 3D). However, a slight difference in the accumulation pattern of the two viruses was noted at later times (Fig. 3E): while LMV-0-GFPHC showed a mosaic of smallish GFP patches, LMV-0-GFPclvHC tended to accumulate in larger, more homogenous patches. Although subtle, these general patterns of GFP expression and accumulation in systemically infected leaves were reproducible in a number of independent experiments.

GFP reporter activity was detected in the roots and in all floral parts of lettuce plants (early flowering line $8720 \mathrm{M}$; Ryder, 1996) infected with the LMV-0 tagged viruses, and especially in the teguments of non-mature seeds. However, differences between LMV-0-GFPHC and LMV-0-GFPclvHC localisation were again noted: only LMV-0-GFPclvHC was able to accumulate in the neck between the style and ovary of non-mature seeds as well as in pollen grains (Fig. 3F and G). In summary, the introduction of the NIa cleavage site between the GFP and the HC-Pro of LMV-0-GFPHC slightly modified the behaviour of the tagged virus in susceptible lettuce varieties and, in particular, allowed the recovery of the ability of the virus to infect some specific reproductive tissues such as pollen.

\subsection{Behaviour of $L M V-0$ and $L M V$-E derived GFP-tagged recombinants in $\mathrm{mol}^{2}$ carrying lettuce}

In lettuce varieties carrying the $m o l^{2}$ gene such as Salinas 88, LMV-E infection results in the appearance of a systemic mosaic at 20 dpi. LMV-0 does not induce symptoms although systemic virus accumulation can be detected albeit at a much lower level than that reached by LMV-E (Revers et al., 1997b; Redondo et al., 2001). However, both LMV-0-GFPHC and LMV-E-GFPHC (or equivalently GUS-tagged recombinants) have been shown to be generally unable to mount a systemic infection of $m o l^{2}$-containing varieties, in contrast to their wild-type parents (German-Retana et al., 2000; Candresse et al., 2002). We therefore investigated whether the introduction of the artificial NIa cleavage site would restore the wild-type biological behaviour of the tagged viruses in resistant plants. GFP fluorescence was monitored in upper non-inoculated leaves of Salinas 88 at 20 and 40 dpi. Unlike LMV-E-GFPHC, LMV-E-GFPclvHC was fully able to move long distances and systemically accumulate in Salinas 88 as shown by the detection of fluorescence and the presence of symptoms at both observation times, the symptoms being similar to those caused by wild-type LMV-E. Analysis of the virus progeny by RT-PCR confirmed the presence of LMV-E-GFPclvHC in these plants (data not shown). By contrast, no systemic accumulation of GFP could be observed using a hand-held 
UV lamp at either time with LMV-0-GFPHC or with LMV-0-GFPclvHC. However, using the more sensitive fluorescence stereomicroscopy, very low level systemic accumulation of GFP was detected in about $15 \%$ of the plants tested (two leaves were observed on a total of 90 plants in three separate experiments). About $9 \%$ of the leaves observed showed at least one very small fluorescent spot (average of 1.5 fluorescent spots per leaf showing at least a spot). These results suggest that the restriction in systemic accumulation of LMV-0-GFPclvHC is not an absolute. ELISA failed to detect the presence of LMV-0-GFPclvHC in the upper non-inoculated leaves of Salinas 88, contrarily to LMV-0 and to the control LMV-0-clvHC which both accumulated to about $15 \%$ of the level reached in the susceptible Salinas variety. Confirming and extending these observations, histochemical GUS staining of systemic leaves of $\mathrm{mol}^{2}$ plants inoculated with LMV-0-GUSHC or LMV-0GUSclvHC failed to reveal any significant systemic accumulation of these recombinant viruses (Fig. $6 \mathrm{~F}$ and data not shown).

These results indicated that the introduction of the NIa cleavage site differentially affects the GFP-tagged recombinants derived from the two LMV isolates. While allowing the recovery of full virulence and of the ability of LMV-E to systemically spread in $\mathrm{mol}^{2}$-containing plants (presence of symptoms, accumulation and detection of fluorescence), the introduction of NIa cleavage site does not allow recovery of the systemic accumulation of wild-type LMV-0.

\subsection{Analysis of the mechanism(s) impairing systemic accumulation of GFP and GUS-tagged LMV-O recombinants in Salinas 88}

In an effort to identify at which level the systemically accumulation of LMV-0 derived recombinants was inhibited in $\mathrm{mol}^{2}$-varieties, the behaviour of LMV-0 tagged viruses, was compared in two near isogenic lettuce varieties, Salinas (susceptible) and Salinas $88, \mathrm{~mol}^{2}$. Seedlings inoculated with LMV-0-GUSclvHC developed GUS infection foci on inoculated leaves at $4 \mathrm{dpi}$, reflecting replication and cell-to-cell movement of the tagged virus on both varieties. No significant difference in the size of the infection foci was found at $4 \mathrm{dpi}$ by histochemical staining between the susceptible and the $\mathrm{mol}^{2}$ varieties (Fig. 5). Similar results ware obtained using LMV-0-GFPHC or GFP-tagged recombinants and epi-fluorescence observation of the inoculated leaves (data not shown).

However, analysis of the size of the infection foci of GUS-tagged recombinants at a later time ( $8 \mathrm{dpi})$ revealed differences in the spread of the virus between susceptible and resistant varieties (Fig. 5A and B). The surface of the infection foci at $8 \mathrm{dpi}$ was, on average, two to three times larger on the susceptible variety than on the resistant one. These results indicated that, irrespective of the presence of an artificial NIa cleavage site, GFP- and GUS-tagged LMV-0 recombinants were able to replicate efficiently and to move

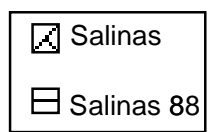

LMV-0-GUSHC

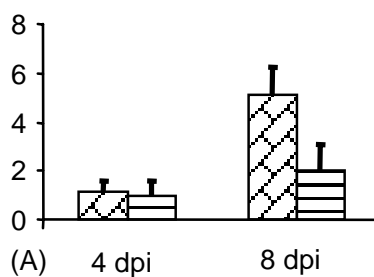

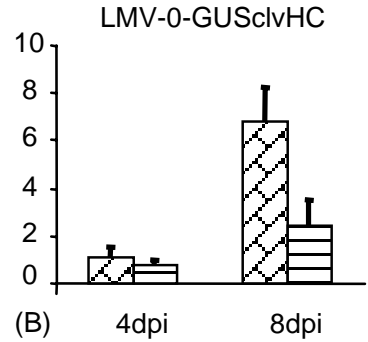

Fig. 5. Time course analysis of the size of infection foci on the inoculated leaves. Time course analysis of the size (expressed in $\mathrm{mm}^{2}$ ) of the infection foci on the inoculated leaves of plants from the varieties Salinas and Salinas 88 infected by LMV-0-GUSHC (A) and LMV-0-GUSclvHC (B). Between 120 and 225 infection foci were measured at 4 dpi for Salinas, and between 32 and 140 for Salinas 88. At 8 dpi, most of the infection foci were confluent, but between 7 on Salinas and 27 on Salinas 88 could be measured. The bars indicate standard deviations.

cell-to-cell in the inoculated leaves of the $m o l^{2}$ cultivar Salinas 88. Data obtained at the early time point (4 dpi) further indicated that the cell-to-cell movement of the recombinants was not severely affected in the resistant plants as compared to the susceptible one.

\subsection{Long distance movement of GFP and GUS-tagged $L M V-0$ is restricted in Salinas 88}

To investigate the phloem loading and unloading of LMV-0-GFPclvHC, grafting experiments were performed. Uninfected Salinas scions were grafted onto Salinas 88 rootstocks which had been pre-inoculated with LMV-0-GFPclvHC 21 days earlier. Controls were composed of healthy Salinas scions grafted onto infected Salinas rootstocks. Thirty days after grafting, symptoms and detection of GFP in the leaves of the Salinas scions demonstrated that in both cases LMV-0-GFPclvHC had moved upwards through the graft junction. The symptoms and fluorescence observed on the Salinas scion grafted on an infected Salinas 88 rootstock were similar to those observed on the control graft combination (Fig. 6B), while no fluorescence or symptoms were seen on the inoculated Salinas 88 rootstock itself (data not shown).

In order to investigate whether the virus was impaired in its ability to unload from the phloem of the resistant variety, graft experiments reciprocal to those described above were performed, in which healthy Salinas 88 scions were grafted onto infected Salinas rootstocks (Fig. 6C-E). Susceptible Salinas scions grafted onto infected susceptible Salinas rootstocks were again used as a control. Thirty days after grafting no symptoms could be seen, but GFP fluorescence was observed on the Salinas 88 scions using a hand-held UV lamp (Fig. 6D). The fluorescence was, however, much less 

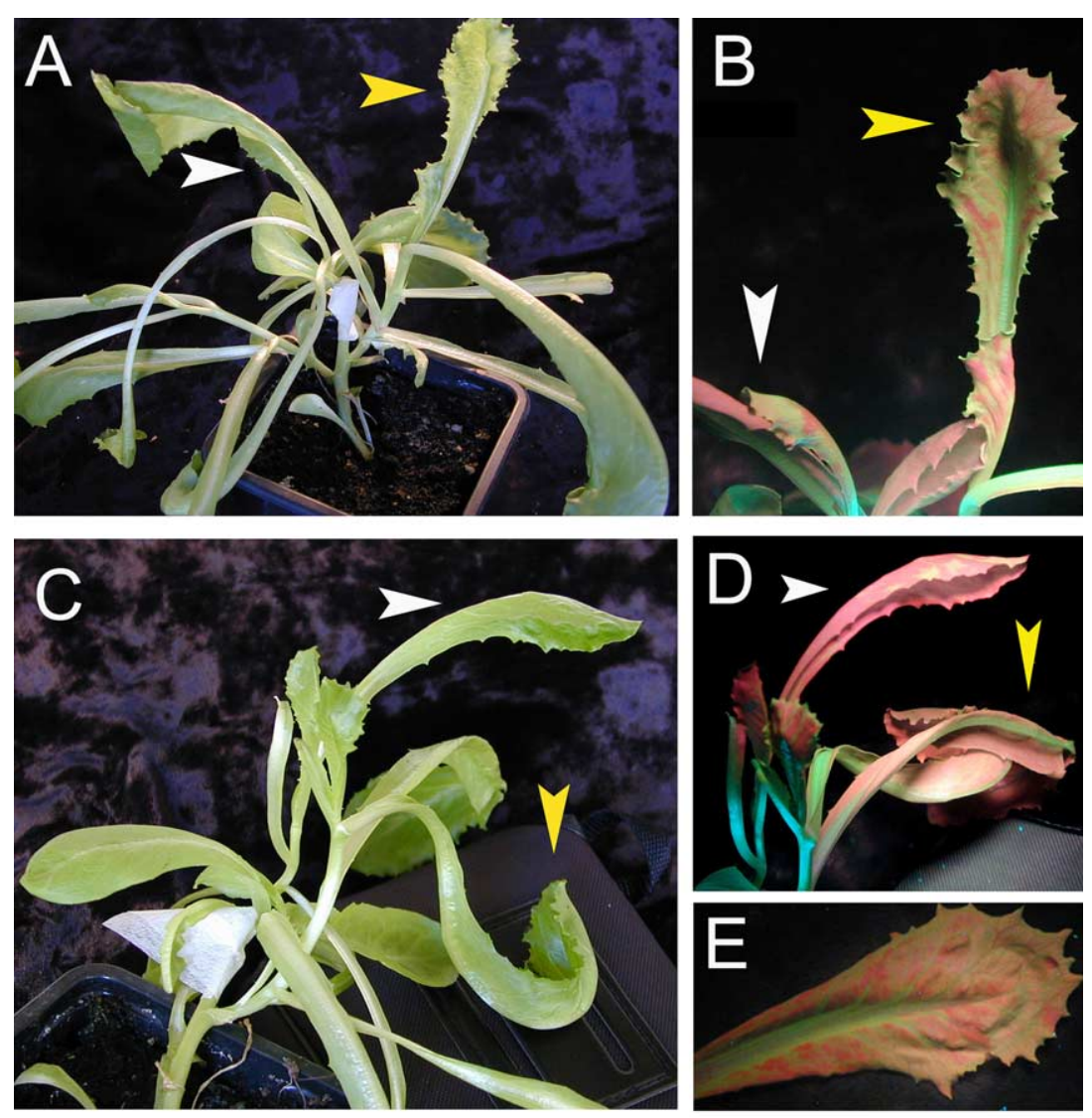

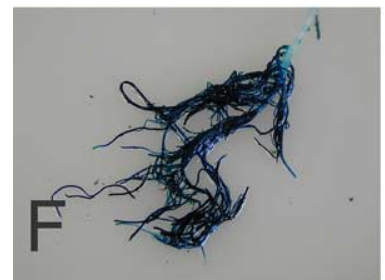

Salinas

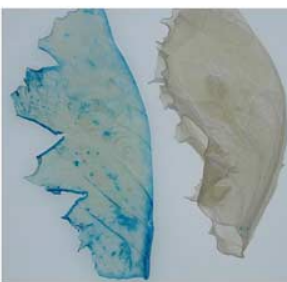

Salinas Salinas 88

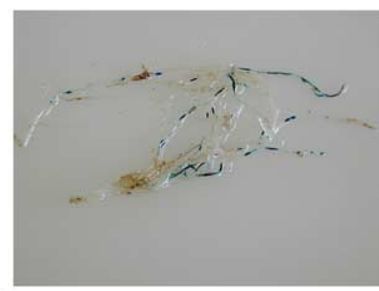

Salinas 88

Fig. 6. Lettuce graft combinations and in situ localization of GUS activity in Salinas and Salinas 88 lettuce. Observation of graft combinations under normal (A, C) and UV (B, D, E) light 30 days after grafting. The white arrowhead indicates the position of the scion leaf, the yellow arrow head the position of rootstock leaf. (A) and (B): Healthy Salinas scions were grafted onto infected Salinas rootstocks infected with LMV-0-GFPclvHC. At the day of grafting, fluorescence was detected under UV light on the Salinas rootstock. Thirty days after grafting, GFP fluorescence and symptoms were present in the Salinas scion (B). (C) and (E): Healthy Salinas 88 scions were grafted onto Salinas rootstocks inoculated with LMV-0-GFPclvHC. At the day of grafting, fluorescence under UV light and symptoms were present on the Salinas rootstock. Thirty days after grafting, GFP fluorescence without symptoms was detected in the Salinas 88 scion (D) but much less than in the Salinas rootstock (E). (F): Detection of LMV-0-GUSclvHC in the roots and upper systemic leaves of Salinas and Salinas 88 at $11 \mathrm{dpi}$.

intense (fewer and smaller GFP patches, lower fluorescence intensity) than on the control Salinas scions (Fig. 6B) or on the Salinas rootstock (Fig. 6E). Furthermore, virus quantification by ELISA indicated that LMV-0-GFPclvHC accumulated in the Salinas 88 scions to only about $40 \%$ of the level reached in the control Salinas scions, and the possibility that the fluorescence detected on the resistant scions was caused by a resistance-breaking virus sequence variant was ruled out by back-inoculations (data not shown).

Further indications that neither phloem loading nor unloading of the recombinant viruses was fully inhibited in the resistant plants came from the analysis of the roots of lettuce plants inoculated with LMV-0-GUSclvHC or LMV-0-GFPclvHC. Table 1 summarises the results of a time-course analysis of the detection of GUS-or GFP-tagged LMV-0 in roots and upper leaves of Salinas and Salinas 88. LMV-0 tagged viruses were detected in the roots of both varieties as early as 4 dpi and at 4, 8, 11, 14, 37 and 70 days post-inoculation, contrary to the situation with upper leaves of Salinas 88 (Table 1). However, irrespective of the analysis time, the recombinant viruses seemed to accumulate systemically in the root system of the resistant variety at a 
Table 1

Time course analysis of the detection of LMV-0-GFPclvHC or LMV-0-GUSclvHC in inoculated leaves, roots and systemic leaves of Salinas and Salinas 88 , after mechanical inoculation

\begin{tabular}{|c|c|c|c|c|c|c|}
\hline & 4 (dpi) & 8 (dpi) & 11 (dpi) & 14 (dpi) & 37 (dpi) & 70 (dpi) \\
\hline \multicolumn{7}{|l|}{ Salinas } \\
\hline Inoculated leaves & + & + & + & n.t. & n.t. & n.t. \\
\hline Systemic leaves & $\varnothing$ & + & + & + & + & + \\
\hline Roots & + & + & + & + & + & + \\
\hline \multicolumn{7}{|l|}{ Salinas 88} \\
\hline Inoculated leaves & + & + & + & n.t. & n.t. & n.t. \\
\hline Systemic leaves & $\varnothing$ & $\varnothing$ & $\varnothing$ & $\varnothing$ & $\varnothing^{\mathrm{a}}$ & $\varnothing^{a}$ \\
\hline Roots & + & + & + & + & + & + \\
\hline
\end{tabular}

Compilation of the data obtained from at least two experiments at each point of the time course (dpi: days post-inoculation). In roots and in inoculated leaves, the presence $(+)$ or absence $(\varnothing)$ of the tagged virus was checked after GUS staining or visualisation of GFP fluorescence, using macroscopic and microscopic imaging. In systemic leaves, ELISA and dot-blot assays were done, to confirm the presence or absence of detectable tagged viruses. n.t.: not tested.

a Sporadic detection by stereomicroscopy of fluorescence.

much reduced level than in the susceptible variety, where only small patches of GUS staining were seen in Salinas 88 roots compared to the susceptible plants (Fig. 6F). Contrary to the situation with the roots, no GUS activity could be detected in the upper leaves of inoculated Salinas 88 plants at the same time point.

Together, the results presented here demonstrated that while GUS and GFP-tagged LMV-0 systemic invasion and accumulation in the upper leaves is greatly impaired in the $\mathrm{mol}^{2}$ variety, neither cell-to-cell movement, nor phloem loading, nor phloem unloading taken separately are fully inhibited in these plants.

\section{Discussion}

During the last decade, the genomes of several potyviruses have been modified to express reporter genes (GUS or GFP) inserted between the P1 and HC-Pro domains, either as a fusion with HC-Pro or with a cleavage site between the reporter gene and HC-Pro, in such a way that a nearly wild-type HC-Pro is produced upon action of the NIa proteinase. The effects of such insertions on the biological properties of the recombinant viruses differ greatly depending on the potyvirus/host combination. Expression of GUS or GFP as a fusion with HC-Pro was not lethal in Tobacco etch virus (TEV) and LMV, although both viruses were somewhat altered in their pathogenicity (Carrington et al., 1993; Schaad et al., 1997; German-Retana et al., 2000; Candresse et al., 2002). The same strategy of GUS fusion to HC-Pro led to loss of infectivity for Plum pox virus (PPV, Guo et al., 1998). Therefore different potyviruses may react very differently to the introduction of HC-Pro N-terminal fusions. Introduction of a NIa cleavage site between GUS and HC-Pro restored infectivity of the recombinant PPV, but not all the biological properties of the wild-type parent (Guo et al., 1998). The same strategy, applied to TEV or Clover yellow vein virus (ClYVV), led to symptoms and to a timing of infection similar to those of the wild-type viruses (Dolja et al., 1997; Masuta et al., 2000).

The results presented here show that introduction of a NIa cleavage site fully restored wild-type biological properties in LMV-E, including its ability to produce symptoms in $\mathrm{mol}^{2}$ plants. The behaviour of similar recombinants derived from LMV-0 was only partially restored, while a control virus with similar alterations of the HC-Pro but lacking a reporter gene had full wild-type properties.

The restriction in long distance movement and in systemic accumulation of the tagged LMV-0 recombinants in $\mathrm{mol}^{2}$ varieties raises several questions. The fact that the restriction was observed in Salinas 88 but not in the near isogenic variety Salinas strongly supports the idea that the restriction is a consequence of the presence of the $\mathrm{mol}^{2}$ resistance gene. Although the wild-type isolate LMV-0 is usually not affected in this way by the resistance, other natural isolates such as LMV-1 and LMV-9 (Dinant and Lot, 1992; Revers et al., 1997b) appear to be similarly affected in systemic accumulation in $\mathrm{mol}^{2}$ varieties.

The systemic movement to the upper non-inoculated leaves appears to be more affected than the downward movement to the root system. In general, viral invasion of the root system has been poorly studied, and in most cases, when analysed, both upward and downward systemic movements were affected. However, similar to the situation reported here with LMV, Guerini and Murphy (1999) showed that in the resistant pepper (Capsicum annuиm) variety Avelar, carrying the recessive gene $p v r 3$, downward movement of Pepper mottle virus (PepMoV) to the roots still occurred while systemic movement to upper non-inoculated leaves was completely blocked due to a block of the entry into the internal phloem. Similar to our observations, albeit in transgenic plants and with another virus, Germundsson et al. (2002) showed that the CP gene-mediated resistance to Potato mop-top virus (PMTV) was expressed differently in roots and leaves.

In a number of virus-plant interactions, a block in upward systemic movement has been linked to the inability 
of the virus to enter the phloem (Rajamäki and Valkonen, 2002; Guerini and Murphy, 1999; Wang et al., 1998) or to the inability to either enter into or exit from the phloem (Hull, 2002; Nelson et al., 1993; Schaad and Carrington, 1996; Thompson and Garcia-Arenal, 1998) and has also frequently been observed to be associated with a reduced rate of cell-to-cell spread (Wong et al., 1999). In the case reported here, the grafting experiments showed that while the upward systemic movement is severely impaired, neither phloem loading nor phloem unloading appears to be completely inhibited. The limited amount of GFP fluorescence observed in resistant Salinas 88 scions grafted onto inoculated susceptible Salinas rootstocks seems to indicate, that phloem unloading or an ensuing step are partially inhibited in the resistant variety. It could be that the erratic way in which low level systemic accumulation is observed in the resistant varieties is caused by cumulative effects at each of the steps along the process: reduced cell-to-cell movement, reduced entry into the phloem, reduced ability to exit the phloem, etc. The alternate hypothesis is the existence, in the resistant plants, of a virus-induced defence signal which moves long-distance via the plant vascular system (Oparka and Turgeon, 1999) and leads to the establishment of a LMV restrictive state in upper non-inoculated tissues. To be compatible with the experimental grafting results, this hypothesis would, in addition, require that the susceptible genotypes be both unable to produce the signal and unable to respond to it.

It is tempting to speculate on the reasons for the substantial differences observed when using similar tagging strategies for different potyviruses or, in the case of LMV, for different strains of the same virus. Given the involvement of HC-Pro in multiple steps of the Potyvirus cycle, including long-distance movement, seed transmission, symptom expression and inhibition of host defences (Klein et al., 1994; Cronin et al., 1995; Johansen et al., 1996; Redondo et al., 2001; Li and Ding, 2001; Kasschau and Carrington, 2001), one possibility is that the observed differences in behaviour reflect minor differences in the tagging strategies. Such differences may result in a variable number of non-viral amino acids being inserted at the $\mathrm{N}$-terminus of the HC-Pro or in variations in cleavage efficiency at the introduced NIa site and thus in the efficiency of the production of the free form of HC-Pro. In the work reported here, introduction of an artificial NIa cleavage site leads to processed HC-Pro with an insertion of two Glycine residues between the first and second amino acids at the N-terminus of HC-Pro. This modification is, however, unlikely to affect the biological properties of the recombinants since LMV-0-clvHC shows a wild-type behaviour for all parameters that we analysed. Similarly, minor modification of the HC-Pro N-terminus in TEV has no marked effect on the biology of the virus, including aphid transmission (Dolja et al., 1998).

Comparison of the behaviour of LMV-0-clvHC with that of its GUS or GFP containing derivatives demonstrates that the introduction of the reporter genes is responsible, directly or indirectly, of the loss of the ability to efficiently accumulate in systemic tissues. At the moment two hypotheses can be proposed to explain this observation. One possibility would be that the presence of an insert $(0.7 \mathrm{kbp}$ for GFP, $1.5 \mathrm{kbp}$ for GUS) and the resulting enlargement of the genome by $7-15 \%$ would "mechanically" slow down viral replication and all subsequent plant invasion processes, which in turn would give a hedge to the plant in the race between viral invasion and plant defence mechanisms such as RNAi (Kasschau and Carrington, 2001). The second possibility would be that the reporter genes fused to HC-Pro could somehow affect one or all of its biological functions (Klein et al., 1994; Cronin et al., 1995; Johansen et al., 1996; Redondo et al., 2001; Li and Ding, 2001; Kasschau and Carrington, 2001). This second hypothesis is in keeping with the observations of Masuta et al. (2000) with ClYVV and Carrington et al. (1993) with TEV which demonstrated complete maturation of the fusion proteins accompanied by complete recovery of the wild-type virus biological properties. In this scenario, the constructs containing an NIa cleavage site would still be producing only about $10 \%$ less of active HC-Pro than the wild-type virus since cleavage between the reporter protein and HC-Pro was never found to be complete. Alternatively, the remaining fused HC-Pro could have a dominant negative effect on some functions exerted by HC-Pro during the virus cycle.

The wild-type behaviour of LMV-0-clvHC could in turn be explained by either a more complete cleavage reaction in the absence of a reporter gene or by a lower detrimental effect on HC-Pro functions due to the more limited structural modifications suffered by the HC-Pro in this context (insertion of only 13 amino acids between the first and second amino acids of the HC-Pro as compared to the insertion of the same 13 amino acids plus the reporter gene in the other constructs). This idea of a limited effect of small extensions to the HC-Pro is supported by the observation that a LMV-E derived recombinant in which the N-terminus of the HC-Pro is tagged by the addition of a poly-histidine tail (total of 10 amino acids added in fusion) retains all biological properties of its wild-type parent (German-Retana, unpublished results; Plisson et al., 2003). The exploration of these hypotheses and in particular the use of site-directed mutagenesis to improve the cleavage efficiency at the synthetic NIa site could further our understanding of the mechanisms involved and possibly allow the development of tagged LMV recombinants sharing all the biological properties of their wild-type counterparts. Nevertheless, the GFP- and GUS-tagged LMV developed by us are useful tools that are already used as expression vector to analyse the interaction between LMV and its host species.

\section{Acknowledgements}

We are grateful to Kathryn Mayo for her help with the English of the manuscript, Thierry Mauduit for taking care of 
the plants in the green-house and the help in the graft experiments, and to our colleagues of the plant-virus interaction group for helpful discussions. This research was partially supported by EPR Aquitaine (ref. 20000307004).

\section{References}

Arazi, T., Slutsky, S.G., Shiboleth, Y.M., Wang, Y., Rubinstein, M., Barak, S., Yang, J., adn Gal-On, A., 2001. Engineering zucchini yellow mosaic potyvirus as a non-pathogenic vector for expression of heterologous proteins in cucurbits. J. Biotechnol. 87, 67-82.

Bannerot, H., Boulidard, L., Marrou, J., Duteil, M., 1969. Etude de l'hérédité de la tolérance au virus de la mosaïque de la laitue chez la variété Gallega de Invierno. Etudes de Virologie. Ann. Phytopathol. $1,219-226$.

Baulcombe, D.C., Chapman, S., Santa Cruz, S., 1995. Jellyfish green fluorescent protein as a reporter for virus infection. Plant J. 7, 10451053.

Bos, L., Huijberts, N., Cuperus, C., 1994. Further observations on variation of lettuce mosaic virus in relation to lettuce Lactuca sativa, and a discussion of resistance terminology. Eur. J. Plant Pathol. 100, 293314.

Brault, V., Candresse, T., Le Gall, O., Delbos, R.P., Lanneau, M., Dunez, J., 1993. Genetically engineered resistance against grapevine chrome mosaic nepovirus. Plant Mol. Biol. 21, 89-97.

Candresse, T., Le Gall, O., Maisonneuve, B., German-Retana, S., Redondo, E., 2002. The use of Green Fluorescent Protein-tagged recombinant viruses to test Lettuce mosaic virus resistance in lettuce. Phytopathology 92, 169-176.

Carrington, J.C., Haldeman, R., Dolja, V.V., Restrepo-Hartwig, M.A., 1993. Internal cleavage and trans-proteolytic activities of the VPg-proteinase (NIa) of Tobacco etch potyvirus in vivo. J. Virol. 67, 6995-7000.

Cheng, N.-H., Su, C.-L., Carter, S.A., Nelson, R.S., 2000. Vascular invasion routes and systemic accumulation patterns of tobacco mosaic virus in Nicotiana benthamiana. Plant J. 23, 349-362.

Clark, M.F., Adams, A.N., 1977. Characteristics of the microplate method of enzyme-linked immunosorbent assay for the detection of plant-viruses. J. Gen. Virol. 34, 475-483.

Cohen, Y., Qu, F., Gisel, A., Morris, T.J., Zambryski, P., 2000. Nuclear localization of Turnip crinkle virus movement protein $\mathrm{p} 8$. Virology 273, 276-285.

Cronin, S., Verchot, J., Haldemann-Cahill, R., Schaad, M.C., Carrington, J.C., 1995. Long-distance movement factor, a transport function of the potyvirus helper component-proteinase. Plant Cell 7, 549559.

De Block, M., Debrouwer, D., 1992. In-situ enzyme histochemistry on plastic-embedded plant material. The development of an artefact-free $\beta$-glucuronidase assay. Plant J. 2, 261-266.

Dinant, S., Lot, H., 1992. Lettuce mosaic virus. Plant Pathol. 41, 528-542.

Dolja, V.V., McBride, H.J., Carrington, J.C., 1992. Tagging of plant potyvirus replication and movement by insertion of $\beta$-glucuronidase into the viral polyprotein. Proc. Natl. Acad. Sci. U.S.A. 89, 1020810212.

Dolja, V.V., Hong, J., Keller, K.E., Martin, R.R., Peremyslov, V.V., 1997. Suppression of potyvirus infection by coexpressed closterovirus protein. Virology 234, 243-252.

Dolja, V.V., Peremyslov, V.V., Keller, K.E., Martin, R.R., Hong, J., 1998 Isolation and stability of histidine-tagged proteins produced in plants via potyvirus gene vectors. Virology 252, 269-274.

Dougherty, W.G., Parks, T.D., Smith, H.A., Lindbo, A., 1990. Expression of potyvirus genome, the role of proteolytic processing. In: Pirone, T.P., Shaw, J.G. (Eds.), Viral Genes and Plant Pathogenesis. Pirone, Springer-Verlag, Vienna. pp. 124-139.
German-Retana, S., Candresse, T., Alias, E., Delbos, R., Le Gall, O., 2000. Effects of green fluorescent protein or $\beta$-Glucuronidase tagging on the accumulation and pathogenicity of a resistance-breaking Lettuce mosaic virus isolate in susceptible ad resistant lettuce varieties. Mol. Plant-Microbe Interact. 13, 316-324.

Germundsson, A., Sangren, M., Barker, H., Savenkov, E.I., Valkonen, J.P.T., 2002. Initial infection of roots and leaves reveals different resistance phenotypes associated with coat protein gene-mediated resistance to Potato mop-top virus. J. Gen. Virol. 83, 1201-1209.

Guerini, M.N., Murphy, J.F., 1999. Resistance of Capsicum annиum 'Avelar' to pepper mottle potyvirus and alleviation of this resistance by co-infection with Cucumber mosaic cucumovirus are associated with virus movement. J. Gen. Virol. 80, 2785-2792.

Guo, H.S., Lopez-Moya, J.J., Garcia, J.A., 1998. Susceptibility to recombination rearrangements of a chimeric Plum pox potyvirus genome after insertion of a foreign gene. Virus Res. 57, 183-195.

Hull, R., 2002. Matthews' Plant Virology, fourth ed., Academic Press, San Diego.

Jefferson, R.A., 1987. Assaying chimeric genes in plants, the GUS gene fusion system. Plant Mol. Biol. Rep. 5, 387-405.

Johansen, I.E., Dougherty, W.G., Keller, K.E., Wang, D., Hampton, R.O., 1996. Multiple viral determinants affect seed transmission of pea seed-borne mosaic virus in Pisum sativum. J. Gen. Virol. 77, 31493154.

Kains, M.G., McQuesten, L.M., 1960. Propagation of Plants, Orange Judd, New York, pp. 300-321.

Kasschau, K.D., Carrington, J.C., 2001. Long distance movement and replication maintenance functions correlate with silencing suppression activity of potyviral HC-Pro. Virology 285, 71-81.

Klein, P.G., Klein, R.R., Rodriguez-Cerezo, E., Hunt, A.G., Shaw, J.G., 1994. Mutational analysis of the tobacco vein mottling virus genome. Virology 204, 759-769.

Li, W.X., Ding, S.W., 2001. Viral suppressors of RNA silencing. Curr. Opin. Biotechnol. 12, 150-154.

MacFarlane, S.A., Popovich, A.H., 2000. Efficient expression of foreign proteins in roots from tobravirus vectors. Virology 267, 29-35.

Masuta, C., Yaman, T., Tacahashi, Y., Uyeda, I., Sato, M., Ueda, S., Matsumura, T., 2000. Development of Clover yellow vein virus as an efficient, stable gene-expression system for legume species. Plant J. $23,539-546$

Nelson, R.S., Li, G., Hodgson, R.A.J., Beachy, R.N., Shintaku, M.H., 1993. Impeded phloem-dependent accumulation of the masked strain of tobacco mosaic virus. Mol. Plant-Microbe Interact. 6, 45-54.

Nicaise, V., German-Retana, S., Sanjuan, R., Dubrana, M.P., Mazier, M., Maisonneuve, B., Candresse, T., Caranta, C., LeGall, O., 2003. The eukaryotic translation initiation factor $4 \mathrm{E}$ (eIF4E) controls lettuce susceptibility to the potyvirus Lettuce mosaic virus. Plant Physiol. $132,1272-1282$.

Oparka, K.J., Roberts, A.G., Santa-Cruz, S., Boevink, P., Prior, D.A.M., Smallcombe, A., 1997. Using GFP to study virus invasion and spread in plant tissues. Nature 388, 401-402.

Oparka, K.J., Turgeon, R., 1999. Sieve elements and companion cells, traffic control centers of the phloem. Plant Cell 11, 739-750.

Pink, D.A.C., Kostova, D., Walkey, D.G.A., 1992a. Differentiation of pathotypes of lettuce mosaic virus. Plant Pathol. 41, 5-12.

Pink, D.A.C., Lot, H., Johnson, R., 1992b. Novel pathotypes of lettuce mosaic virus. Breakdown of a durable resistance. Euphytica 63, 169174.

Plisson, C., Drücker, M., Blanc, S., German-Retana, S., Le Gall, O., Thomas, D., Bron, P., 2003. Structural characterisation of HC-Pro, a plant-virus multifunctional protein. J. Biol. Chem. 278, 2375323761.

Rajamäki, M.L., Valkonen, J.P.T., 2002. Viral genome linked protein (VPg) controls accumulation and phloem-loading of a potyvirus in inoculated potato leaves. Mol. Plant-Microbe Interact. 15, 138149 . 
Redondo, E., Krause-Sakate, R., Yang, G., Lot, H., Le Gall, O., Candresse, T., 2001. Lettuce mosaic virus pathogenicity determinants in susceptible and tolerant lettuce varieties map to different regions of the viral genome. Mol. Plant-Microbe Interact. 14, 804-810.

Reichman, J.L., Lain, S., Garcia, J.A., 1992. Highlights and prospects of potyvirus molecular biology. J. Gen. Virol. 73, 1-16.

Revers, F., Yang, S.J., Walter, J., Lot, H., Souche, S., Le Gall, O., Candresse, T., Dunez, J., 1997a. Comparison of the complete nucleotide sequences of two isolates of Lettuce mosaic virus differing in their biological properties. Virus Res. 47, 167-177.

Revers, F., Lot, H., Souche, S., Le Gall, O., Candresse, T., Dunez, J., 1997b. Biological and molecular variability of lettuce mosaic virus isolates. Phytopathology 87, 397-403.

Roberts, A.G., Santa Cruz, S., Roberts, I.M., Prior, D.A.M., Turgeon, R., Oparka, K.J., 1997. Phloem unloading in sink leaves of Nicotiana benthamiana, comparison of a fluorescent solute with a fluorescent virus. Plant Cell 9, 1381-1396.

Roudet-Tavert, G., German-Retana, S., Delauney, T., Delecolle, B., Candresse, T., Le Gall, O., 2002. Interaction between potyvirus helper component-proteinase and capsid protein in infected plants. J. Gen. Virol. 83, 1765-1770.

Ryder, E.J., 1970. Inheritance of resistance to common lettuce mosaic. J. Am. Soc. Horticult. Sci. 95, 378-379.

Ryder, E.J., 1991. Salinas 88 Lettuce. Hort. Sci. 26, 439-440.

Ryder, E.J., 1996. Ten lettuce genetic stocks with early flowering genes Ef-1ef-1 and Ef-2ef-2. Hort. Sci. 31, 473-475.
Schaad, M.C., Carrington, J.C., 1996. Suppression of long distance movement of tobacco etch virus in a non susceptible host. J. Virol. 70, 2556-2561.

Schaad, M.C., Lellis, A.D., Carrington, J.C., 1997. VPg of tobacco etch potyvirus is a host genotype-specific determinant for long distance movement. J. Virol. 71, 8624-8631.

Sudarshana, M.R., Wang, H.L., Lucas, W.J., Gilbertson, R.L., 1998. Dynamics of Bean dwarf mosaic geminivirus cell-to-cell and long distance movement in Phaseolus vulgaris revealed using the green fluorescent protein. Mol. Plant-Microbe Interact. 11, 277-291.

Thompson, J.R., Garcia-Arenal, F., 1998. The bundle sheath-phloem interface of Cucumis sativus is a boundary to systemic infection by Tomato aspermy virus. Mol. Plant-Microbe Interact. 11, 109-114.

Wang, H.L., Wang, Y., Giesman-Cookmeyer, D., Lommel, S.A., Lucas, W.J., 1998. Mutations in viral movement protein alter systemic infection and identify an intercellular barrier to entry into the phloem long distance transport system. Virology 245, 75-89.

Wang, H.L., Sudarshana, M.R., Gilbertson, R.L., Lucas, W.J., 1999. Analysis of cell-to-cell and long-distance movement of a Bean dwarf mosaic geminivirus-green fluorescent protein reporter in host and non-host species: identification of sites of resistance. Mol. Plant-Microbe Interact. $12,345-355$.

Wong, S.M., Swee-Chin Thio, S., Shitaku, M., Palukaitis, P., 1999. The rate of cell-to-cell movement in squash of Cucumber mosaic virus is affected by sequences of the capsid protein. Mol. Plant-Microbe Interact. 12, 628-632. 